\title{
Diplomacy in Times of Disaster: Management through Reputational Capital
}

\author{
Liza Ireni-Saban \\ Interdisciplinary Center (IDC) Herzliya
}

The 6.6 magnitude quake event that occurred in 2003 (Bam, Iran) made it impossible for the Iranian government to handle disaster relief efforts domestically. In this extreme event, the Iranian government reached out to the international community, and this created a momentum that had to be carried out by trust-building efforts on all sides, often termed "Disaster Diplomacy". This paper suggests that the postdisaster setting may benefit from using the ecology of games framework to evaluate the role of bridging actors and mediators in facilitating collaborative governance networks. Recent developments in network theory and analysis provide means of structural embeddedness to explore how reputational capital can be built through brokerage roles of actors engaged in a disaster management network. This paper then aims to structure the relations among actors that participated in the post-disaster relief efforts in the 2003 Bam earthquake (Iran) in order to assess under which conditions actors may be strategically utilized to serve as mediating organizations for future disaster events experienced by isolated nations or nations in conflict. The results indicate the strategic use of reputational capital by the Iranian Ministry of Foreign Affairs as key broker to build a successful coordinative system for reducing disaster vulnerabilities. International aid agencies rarely played brokerage roles to coordinate peripheral actors. USAID, despite coordination capacities, was prevented from serving brokerage roles in the system.

\section{INTRODUCTION}

During December 2003, the 6.6 magnitude quake event made it impossible for the Iranian government to handle the disaster relief efforts domestically. In this extreme event, the Iranian government reached out to the international community, and this created a momentum that had to be carried out by trust-building efforts on all sides, often termed "Disaster Diplomacy" (Kelman, 2006). Indeed, the circumstances were even more acute when one considers the increasing political and economic isolation of Iran within the international community (UNOCHA, 2004; Wood, 2004). The potential for transformative political space to be opened by disaster has been recognized by dominant international political actors. USAID (2004) describes post-disaster political spaces as: "Moments when underlying causes [of conflict] can come together in a brief window, a window ideally suited for mobilizing broader violence. But such events can also have extremely positive outcomes if the tensions ... are recognized and handled well."

Despite the fact that Bam 2003 post-disaster relief efforts did not catalyze any diplomatic activities on all sides, it is suggested that few international aid agencies have successfully used disaster recovery to enhance their popular legitimacy and reputation among the international community. In terms of disaster diplomacy, an actor's reputational capital may affect his ability to build coalitions and alliances to achieve 
international political ends, to negotiate and build understanding and trust with foreign publics (Wallensteen \& Svensson, 2014). The concept of reputational capital is broadly defined as an intangible asset that engenders credibility, shared trust, and affinity among multiple actors. The capacity to share information and expand reputations more broadly within networks may increase the scope for mutually advantageous relations among actors engaged in these networks (Mueller, Schmidt \& Kuerbis, 2013; Singh, 2013). While most studies have demonstrated the possibility that reputational capital can enhance collaboration (Lassa, 2012; Magsino, 2009; Varda, Forgette, Banks \& Contractor, 2009; Wise, 2006), less is known about how such capacity is structurally embedded in a network to facilitate coordination efforts.

This paper then aims to focus on positional elements of the disaster management network that emerged during the post-disaster relief efforts in the 2003 Bam earthquake in order to assess under which conditions actors may be strategically utilized to serve as mediating organizations for future disaster events experienced by isolated nations or nations in conflict. By discerning patterns of interactions between members in a network of embedded ties, reputational capital is operationalized through the structural position actors occupy in the disaster management network. Actors occupying brokerage positions may complement the scarcity of information and resources (Ingold, 2011; Mashaw, 2006). Our network approach draws on the revived and updated "ecology of games" (EG) concept offered by Lubell, Henry \& McCoy (2010), which values bridging social capital involving intensive ties, reciprocity, and centralized brokers when coordination problems prevail in a particular geographic region (Lubell et al., 2010).

Using evidence from the Bam (Iran) 2003 disaster, this paper corroborates patterns of interactions and positional structures among various members engaged in disaster relief efforts by using the G\&F brokerage roles framework. In a disaster setting, actors would presumably search bridging network structures that provide them with efficient and reliable information exchange to facilitate disaster relief efforts (Berardo \& Scholz, 2010). It is suggested that this case provides a setting by which we can further explore the strategic use of brokers to mobilize an effective response system and to lay the groundwork for later diplomacy. This article is organized in three sections. The first section presents the relevance of structural embeddedness to network analysis, which offers insights into patterns of interactions and strategic reputational capacity building in the post-disaster recovery phase. The methodological section introduces social network analysis (SNA) to identify the structural relationships and positions among interacting members within a disaster management network. The third section presents empirical evidence from the selected case study to assess the role of brokerage in increasing reputational capital for effective coordination in relief efforts in Bam (Iran) 2003.

\section{Structural Embeddedness of Reputational Capital in a Disaster Management Network}

The concept of reputational capital refers to features of social interaction that create an environment of mutual benefit and coordination. Coordination is considered a prerequisite for cooperative and by extension collaborative efforts. Collaborative interaction signifies the final phase of agency interaction; its functioning involves the establishment of a previously coordinative and then cooperative relationship (Gajda, 2004; Hanaki, Peterhansl, Dodds \& Watts, 2007; Hogue, 1993). Coordination provides information to different actors of the desired outcome in a given transaction while cooperation evolves in the recognition of each actor to invest in social capital and social underpinnings necessary to create mutually beneficial tradeoffs (e.g., better outcomes for all partners) (Ireni-Saban, 2015). Within the framework of social relations and networks, reputational capital is broadly defined as an intangible asset that is inherent in networks formed by goal orientation and shared trust (Fombrun, 1996; Gardberg \& Fombrun, 2006). According to Thompson, trust is conceived as a fundamental norm of social networks; it is "established to precisely economize on transactions costs" (Thompson, 2003: 32). Norms of trust and reciprocity are expected to increase the level of coordination by reducing uncertainty surrounding a partner's behavior and predict his future actions; "trust implies an expected action ... which we cannot monitor in advance, or the circumstances associated with which we cannot directly control. It is a kind of device for coping with freedoms of others. It minimizes the temptation to indulge in purely opportunistic 
behavior" (Thompson, 2003: 46). Thus, social network theorists have linked horizontal relationships with collaborative behaviors and norms of trust and reciprocity (Thompson, 2003).

Governance network studies have adopted this conceptualization at the organizational level, recognizing that the benefits of strategic networking include a markedly collaborative advantage that compensates for scarcity of information and uncertainty (Börzel, 1998; deLeon \& Varda, 2009; Fombrun, 1996: 11-12; Hall, 1993: 608). Network settings exemplify a dynamic set of integrative working arrangements among voluntary participants for reducing uncertainty and solving problems. Reputation then substitutes for costly mechanisms that are used to verify the intentions and monitor the actions of network actors (Morris, Morris \& Jones, 2007). A negative reputation can actually hurt collaboration among partners where positive reputation in general leads to greater collaboration (Polzer, 2004). Clearly, an asset of such great value should be managed to its utmost advantage to build and preserve a positive sum of perceptions including credibility, reliability, and responsibility concerning the performance of all relevant actors, taking time to build but easily harmed even after long years of existence (Fombrun, 1996: 11-12; Hall, 1993: 608).

At first sight it seems odd that reputational capital, which qualifies as a unique core competency with a long-term dimension, can be stimulated by sudden events such as natural disasters. However, in this paper we suggest that a large-scale disaster event that requires high levels of interaction and coordination amongst a wide array of actors engaged in response and relief efforts can be strategically used to build capabilities to enhance reputation amongst participating actors. By drawing on the structural embeddedness of networks, reputational capital may mitigate behavioral uncertainty when selecting collaborative partners (Gulati \& Gargiulo, 1999; Meuleman, Amess, Wright \& Scholes, 2009; Uzzi, 1997). Embeddedness is claimed to create information-sharing routines and joint problem solving among actors (Uzzi, 1997). Thus, it is suggested that developing a network of embedded ties may create opportunities for building reputational capital. Structural embeddedness in an emergency response network may face severe problems of isolation as agencies create their own clusters or sub-groups in which they maintain strong ties within clusters, while clusters do not build ties with other clusters (IreniSaban, 2015). Structural embeddedness falls short at explaining the conditions under which actors may seek out and collaborate with new partners in order to access new knowledge and opportunities, thereby increasing adaptability to changing realities (Meuleman et al., 2009; Rowley, Behrens \& Krackhardt, 2000). However, structural embeddedness is less salient for selecting partner actors when potential partner actors have established reputational capital in the governance network (Meuleman et al., 2009). In fact, recent studies suggested that reputational capital may act as a partial substitute for structural embeddedness because of knowledge complementarities that mitigate the risk of opportunism (Meuleman et al., 2009; Robinson \& Stuart, 2007; Shane \& Cable, 2002).

\section{Brokerage Role and Reputation Capital in Governance Network}

The question remains of how the embedded structure of a governance network can stimulate reputational capital to enhance collaboration among actors engaged in response and relief efforts (Ingold, 2011). This paper focuses on the structural dimension of reputational capital indicated by coordination activities rather than the relational dimension entrenched in collaborative activities (see Figure 1) (Dentchev \& Heene, 2004; Gajda, 2004). Studies have long stressed the failure of coordination as a central factor in explaining poor performance during recovery phases in disaster management (Comfort \& Haase, 2006; Comfort, Ko \& Zagorecki, 2004; Drabek, 2003; Kapucu, 2006; Kapucu, Arslan \& Collins, 2010; Kapucu, Augustin \& Garayev, 2009; Kobila, Meek \& Zia, 2010; McEntire, 2002; Mitchell, 2006; Moynihan, 2012). When this institutional complexity is examined from the conceptualization of the "ecology of games", the strategic structure and payoffs may be interconnected through political process, so that disaster management decisions regarding relief efforts may directly influence payoffs in other policy, e.g., diplomacy or international, relations (Lubell, 2013). Actors participating in coordination efforts constitute the ecology of the game at hand in a specific policy system, and each game raises different opportunities for involved actors to capture the greatest gains from cooperation to build their bridging capacities (Smaldino \& Lubell, 2014).

Journal of Management Policy and Practice Vol. 20(3) 2019101 


\section{FIGURE 1 \\ FACETS OF REPUTATIONAL CAPITAL IN GOVERNANCE NETWORKS}

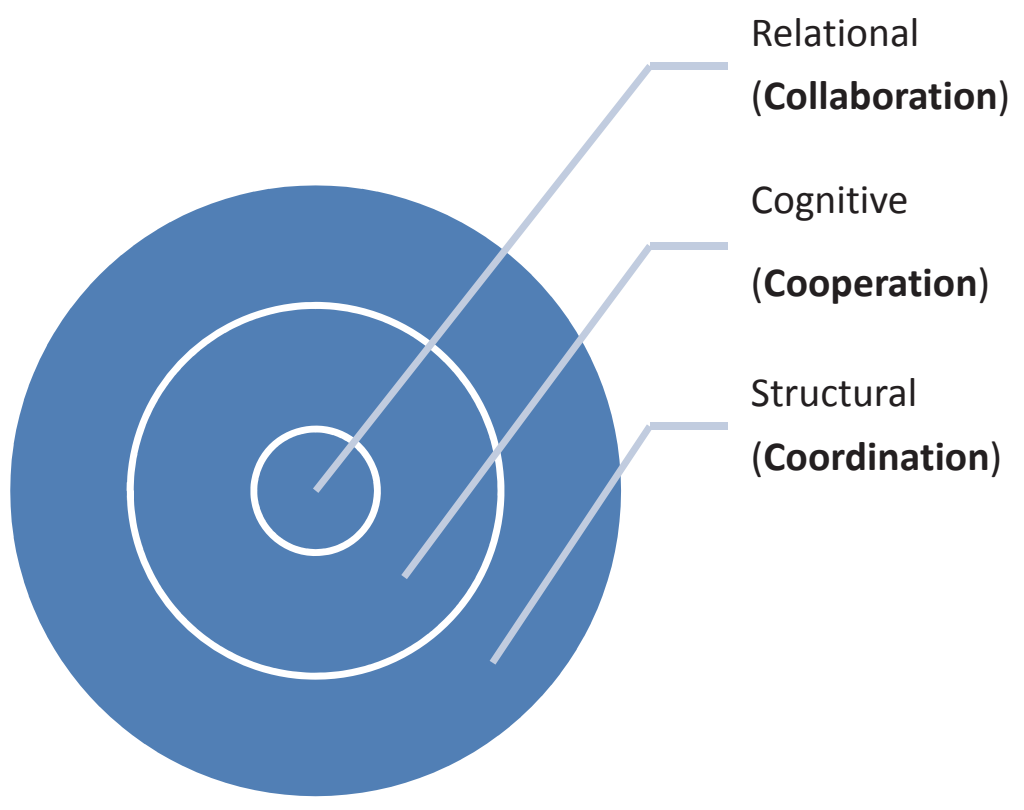

Structural embeddedness, the structural positions actors occupy in a network, may enable them to build their reputational capital. Such positions may reduce the specific transaction costs, such as imperfect information about potential partners in a highly time-constrained environment, that are barriers to coordination and by extension collaboration (Keast, Mandell, Brown \& Woolcock 2004; Mueller et al., 2013; Singh 2013). During disaster events, governance networks tend to become less dense and thus likely to provide more strategic opportunities for mediating actors. In this less dense network, actors may face severe problems of isolation that may challenge their access to critical information and resources, and only those actors endowed with reputational capital may play a critical role of connecting fragmented clusters. These structural positions, often termed "structural holes" or "weak spots", can be strategically occupied by brokers having reputational capital and the flow of information and resources becomes more efficient and effective (Burt, 1992; Marsden, 1982). It should be noted that brokers do not necessarily rely on their own resources and information, but rather they may have access to or control of the flow of resources and information among other actors, and they benefit from their embedded positions in a network.

This study discerns four main types of structural embeddedness in an emergency response network. Some actors are isolated from others, others take the dominant position in the network and serve as coordinators, some are more peripheral in that their interactions depend mostly on the coordination of brokering agencies, and other agencies take brokerage roles and strategically use their embeddedness in the network and their reputational capital to achieve the shared goal of the network.

Gould \& Fernandez (1989) profiled five types of brokerage roles among interacting network members - ego-network. In ego-network each actor is connected to every other actor in the network. Nevertheless, there could be members of the network who are not connected directly to one another, and if only ego has connections with other members of the network, ego may serve as a broker. In terms of structural positions, ego falls on the paths between the other actors in the network (Hanneman \& Riddle, 2005). The five types of brokerage roles are: coordinator, consultant, gatekeeper, representative, and liaison. The coordinator is an agency that brokers a relation between two members of the same group; the consultant brokers a relation between two members of the same group, but is not itself a member of that group; the gatekeeper is a member of a subgroup that is at the boundary and controls access of external members to the group; the representative is a member of a subgroup that represents that group in connection with 
external partners; and liaison is a brokering agency that connects a relation between two groups, but is not part of either group (Hanneman \& Riddle, 2005). Operationalization of reputational capital through structural proprieties of networks, such as brokerage roles in a disaster setting, is utilized by techniques of social network analysis (SNA).

\section{Case Study}

The article uses case study of the disaster event that occurred at the end of December 2003 in Bam (Iran). The 6.6 magnitude quake caused the death of more than 30,000 people, with an estimate of more than 25,000 injured. In addition, it was reported that about $80 \%$ of the town's buildings had collapsed, which left 70,000 people homeless (USAID, 2004). Although the Iranian government's initial reaction to the offers of humanitarian assistance was to try to avoid accepting external help, the massive destruction revealed failed systems of engineering, economics, public safety and health, logistics, and recovery. These failures in disaster planning and management were intensified by poorly coordinated responses between all levels of government and across the local, voluntary, and private sectors. The response system involved 354 agencies actively participating in the response system, 234 organizations $(66.1 \%)$ were isolated from other agencies, meaning that their disaster relief activities were made without interactions with partnering agencies. Further, of the organizations coordinating with partnering agencies 178 (50.2\%) were international. This figure indicates the realization of the Iranian government during the disaster relief phase that such activities cannot be handled domestically (Table 1).

\section{TABLE 1}

\section{DESCRIPTIVE STATISTICS OF 2003 IRAN DISASTER RESPONSE NETWORK}

\begin{tabular}{|c|c|c|c|c|c|c|}
\hline & & $\frac{\text { Total Number }}{\text { of Actors }}$ & $\begin{array}{c}\frac{\text { Number of }}{\text { nun-isolated }} \\
\text { actors }\end{array}$ & 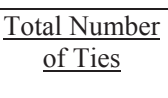 & $\frac{\frac{\text { Average Ties }}{\text { per non- }}}{\text { isolated Actor }}$ & $\begin{array}{l}\text { Percentage of } \\
\text { Isolated actors }\end{array}$ \\
\hline & Total & 354 & 234 & 711 & 1.332 & 66.1 \\
\hline $4 . ?$ & International & 150 & & & & \\
\hline 0.0 & National & 50 & & & & \\
\hline$\Xi$ & Regional & 43 & & & & \\
\hline & Local & 111 & & & & \\
\hline
\end{tabular}

\section{METHODOLOGY}

This paper explores structural embeddedness and brokerage roles in post-disaster recovery efforts in Iran based on empirical data collected over a seven-year period (2003-2010). In order to corroborate coordination patterns of interaction among actors engaged in response and relief efforts, we created an ordinal scale for measuring the interconnectedness and frequency of linkages between organizations ranging from no interaction to strong interaction associated with frequent communication, and exchange of information and resources on regular basis (Houge, 1993; Mann, Cao, \& Mann, 2011). The data was then analyzed by means of social network analysis using UCINET 6 software, as well as qualitative analysis, from which the conclusions in this research are derived.

(1) Data collection and mapping: the collected data for this study issued from content analysis of SitReps (situation reports) that documented, among other issues, response activities. Empirical data consist mostly of nearly 455 SitReps, which include daily updates of a disaster event in a specific country. News articles and reports drawn from agency websites such ReliefWeb.net, UNESCO, United Nations Office of the Coordination of Humanitarian Affairs (OCHA), USAID, UNISDR, World Bank, iran.ir, IFRC, SCI, AlertNet, RADIX, IRC, and IRNA. One hundred and twenty organizations that coordinated with other organizations in the network from 2003 to 2010 were identified. Additionally, governmental and international agencies' reports, statements, press releases, and committees' consultation responses were collected using Lexis-Nexis software. 
This period covered the response efforts that were handled by governmental, local, and international agencies. It should be noted that the corpus of SitReps was particularly useful for the data analyzed here, as they are publicly accessible and provide well-defined temporal coverage given the fact that websites of various organizations engaged in the international emergency management system contained misdated or distorted data sources. The next step in the formation of the interorganizational network of the 2003 Bam disaster response was to identify the coordinative relationship among participating organizations. Coordination refers to an immediate component of disaster response because of the sheer numbers of actors that engaged in the affected area. Since the organizational structures vary across different types of organizations (centralized (governmental agencies) vs. decentralized (NGOs)) as well as their operations (top down vs. bottom up) and their length of commitment (short-term vs. long-term), in this study we used an ordinal scale for measuring the strength of interagency linkages drawing on the community linkages matrix by Hogue (1993). The unit of analysis was interorganizational relationships; therefore, qualitative analysis was used to establish the rating that identifies the depth and complexity of linkages between organizations. The reported interactions were coded using a value matrix in which the intensity of the connections between the actors was valued between 0 (no interaction) and 3 (for a strong interaction). A rating of 0 identifies that two organizations coexist in the network and that they have no regular contact or relationship; a rating of 1 indicates a level of weak relationship with little communication, loosely defined roles, and all decisions and response efforts are made independently; a rating of 2 indicates more frequent communication and somewhat defined roles, while all response efforts are made independently; a rating of 3 indicates strong relationships with frequent communication, existence of permanent associations that serve to share and exchange disaster needs assessments and information, resources, and lessons learned through regular exchange of information (Coppola, 2011; Hogue, 1993).

(2) The structured data from content analysis was used as an input to social network analysis (SNA). To run UCINET 6 software (Borgatti, Everett \& Freeman, 2002), we produced a mode network (organization $\times$ organization matrix) using the coded interactions. Social network analysis differs substantially from the statistical analysis used in governance studies. SNA assumes interdependence between actors in networks, focusing on relationships and interactions rather than on actors' attributes. Power is conceived in terms of occupying advantageous positions in networks of relations. Three network centrality measures were calculated as sources of advantage: degree, closeness, and betweenness. Degree measures the immediate ties that an actor has, closeness measures the distance of an actor to all others in the network by focusing on the geodesic distances from each actor to all others, and betweenness measures the number of times an actor falls on the geodesic paths between other pairs of actors in the network, which indicates the extent to which such an actor can play the role of a broker (Hanneman, 2001). In addition, we used UCINET 6 software to calculate and identify the number of brokerage roles played by different actors based on G\&F brokerage roles typology (it should be noted that all isolated organizations were removed from the initial network for ego-network analysis). G\&F Brokerage role analysis requires a partition vector indicating the membership of an actor in a network. The frequency distribution of the number of brokerage roles that each ego node played during the response phase was created from ego network analysis and G\&F Brokerage roles analysis.

The functions for positional and role analysis that each ego node played during the response phase was created from ego network analysis and G\&F Brokerage roles analysis (Borgatti et al., 2002). The application of social network analysis does suffer from several shortcomings. The data collected might be biased as most interactions are self-reported. In the case of Iran, recorded data collection was complex due to the experience of almost thirty years of isolation from the international community, which imposed constraints on the access to state and local NGOs' resources and information. In addition, the data used in network analysis concerns ties among organizations rather than data on the attributes of each organization such as data on members represented in these organizations, which could indicate the extent of an organization's fragmentation, which can undermine its functionality (Lubell, 2013). It should be noted that the model itself isn't explicitly designed to include noncooperative strategies into the mix of games and thereby reduce the consistency of the overall evolution of cooperation process. 


\section{FINDINGS AND DISCUSSION}

Bam 2003. A visual representation of the overall network of organizations' interactions in community resilience efforts in Iran is presented in Figure 2. As indicated, the logic underlying measures of degree centrality is that actors who have more ties have greater opportunities, which makes them less dependent on any specific other actor, and hence more powerful (Hanneman, 2001). Table 2 presents the measures of degree of centrality. According to Table 2, MOFA has the highest degree of centrality level, followed by UNOCHA (which means that other actors in the network seek to have ties to them, and this may indicate their importance). Among the 200 international organizations that arrived in Bam in the first two weeks after the earthquake, the UN Office for the Coordination of Humanitarian Assistance (OCHA) directly coordinated with the Iranian government. UNOCHA set up a camp to enhance system-wide coordination among international relief NGOs. For that purpose, UNOCHA established sectoral coordination meetings and strengthened links with the Iranian Red Crescent (Pinera, Reed \& Njiru, 2005) The IRCS, Iran's largest relief organization, also coordinated with both governmental agencies such as MOFA and MOI as well as with UNCHO. The IRCS, the lead agency for the disaster relief efforts, collected information on surviving families and their needs, and coordinated the search and rescue along with coordinating emergency efforts and food distribution in Bam. The IRCS initiated one of the formal coordinating systems, which divided the city of Bam into 12 zones, each to be assisted by a different provincial branch. It should be noted that such coordinating effort was rapidly picked up by international NGOs, who agreed to accept assigned zones and to concentrate their relief efforts in these areas (Wood, 2004).

\section{FIGURE 2 \\ MAP OF ACTORS' INTERACTIONS IN POST-DISASTER GOVERNANCE NETWORK IN IRAN}

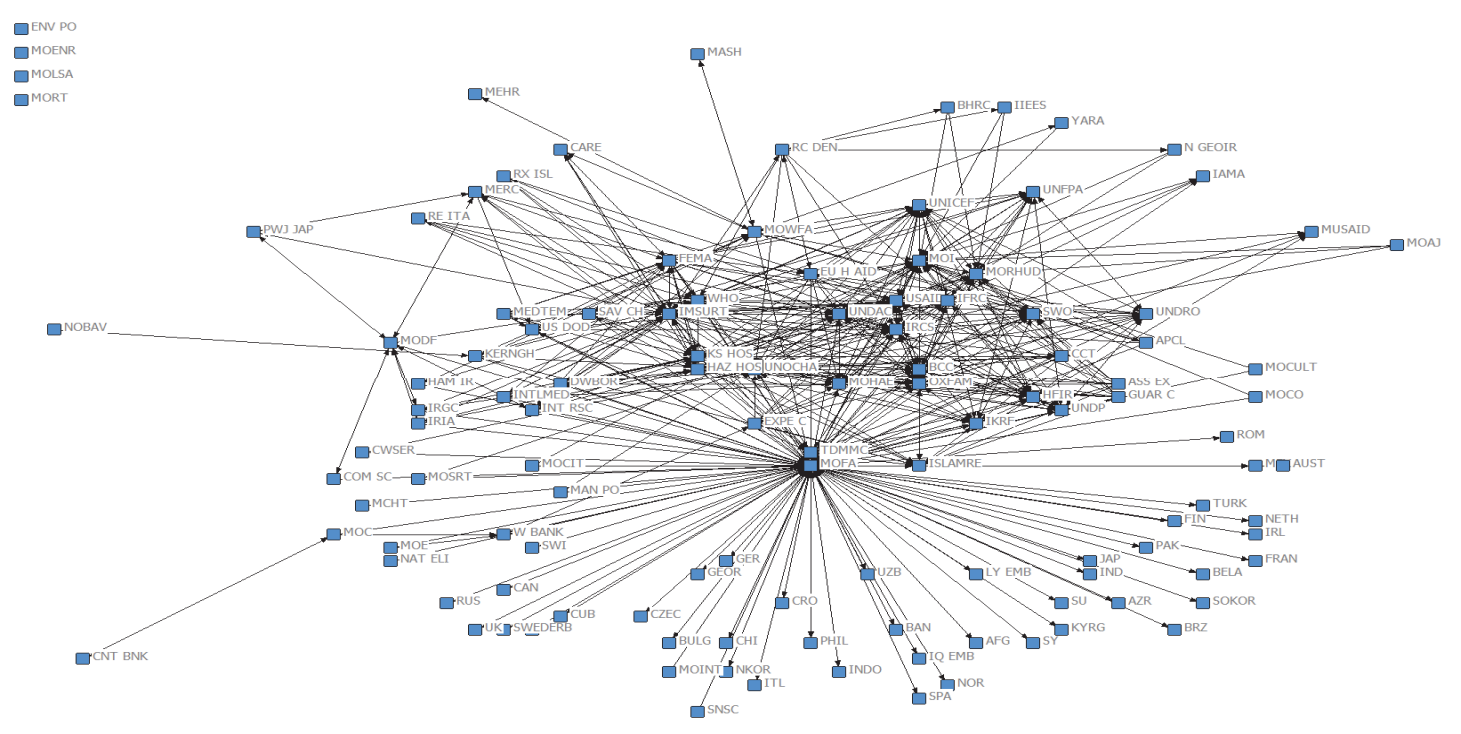


TABLE 2

DEGREE OF CENTRALITY

\begin{tabular}{llll}
\hline & Degree & NrmDegree & Share \\
\hline Mean & 18.983 & 5.317 & $\mathbf{0 . 0 0 8}$ \\
Std Dev & 29.866 & 8.366 & $\mathbf{0 . 0 1 3}$ \\
Sum & 2278.000 & 638.095 & $\mathbf{1 . 0 0 0}$ \\
Variance & 891.950 & 69.985 & $\mathbf{0 . 0 0 0}$ \\
SSQ & 150278.000 & 11791.227 & $\mathbf{0 . 0 2 9}$ \\
MCSSQ & 107033.969 & 8398.181 & $\mathbf{0 . 0 2 1}$ \\
Euclidean Norm & 387.657 & 108.587 & $\mathbf{0 . 1 7 0}$ \\
Minimum & 0.000 & 0.000 & $\mathbf{0 . 0 0 0}$ \\
Maximum & 241.000 & 67.507 & $\mathbf{0 . 1 0 6}$ \\
& & & \\
Network & $63.24 \%$ & & \\
Centralization $=$ & & & \\
Heterogeneity $=$ & $2.90 \%$ & & \\
Normalized $=$ & $2.08 \%$ & NrmDegree & Share \\
& Degree & 67.507 & $\mathbf{0 . 1 0 6}$ \\
MOFA & 241.000 & 26.891 & $\mathbf{0 . 0 4 2}$ \\
UNOCHA & 96.000 & 23.810 & $\mathbf{0 . 0 3 7}$ \\
MOI & 85.000 & 20.448 & $\mathbf{0 . 0 3 2}$ \\
IRCS & 73.000 & 19.048 & $\mathbf{0 . 0 3 0}$ \\
WHO & 68.000 & 17.927 & $\mathbf{0 . 0 2 8}$ \\
UNDAC & 64.000 & 17.087 & $\mathbf{0 . 0 2 7}$ \\
IFRC & 61.000 & 16.807 & $\mathbf{0 . 0 2 6}$ \\
UNICEF & 60.000 & 16.527 & $\mathbf{0 . 0 2 6}$ \\
USAID & 59.000 & S &
\end{tabular}

$\mathrm{SSQ}=$ Sum of Squares; MCSSQ=Mean Centered Sum of Squares

In this case, the network centralization is $63.24 \%$, which leads to the conclusion that there is a high amount of concentration or centralization in this whole network. A higher level of variability indicates that positional advantages are not equally distributed in this network. However, degree of centrality may take into account only the immediate ties of an actor. Thus, we need to add other measures such as closeness centrality to assess the structural advantage exerted by direct bargaining and exchange, such as the geodesic distances for each actor. Table 3 presents the measure of closeness centrality. We can see that MOFA and UNOCHA are the closest or most central actors using this measure, because the sum of these actors' geodesic distances to other actors is the minimum possible sum of geodesic distances (the least farness). MOFA has pooled facilities world-wide to aid the quake victims, and it has closely coordinated with the MOI, IRCS, and UNOCHA to allow international organizations to send all their potential facilities to the affected region as well as maintaining communication channels with leaders of countries around the world who offered different forms of aid to Iran.

Table 3 points to MOFA, which scored relatively high in closeness centrality; thus it possesses structural advantage exerted by direct bargaining and exchange, such as the geodesic distances for each actor, rather than creating immediate ties with other actors in the network. The figure also points out that HFIR is scored relatively high in closeness centrality but lower in other dimensions. The HFIR is a nonprofit public organization established in 1979 by the order of Imam Khomeini, the founder of the Islamic Republic of Iran, which had a key role in reconstruction efforts in the post-disaster phase by providing housing for the disaster-affected communities (HFIR, 2009). During the post-disaster 
reconstruction activities, HFIR offered to use new techniques in construction of housing units. A technical team was formed by HFIR and was sent to rural areas. However, this project demanded coordination between "rural councils", which HFIR could not monitor by itself. HFIR had to first coordinate with Bam's reconstruction Steering Committee, headed by both the minister of housing and urban development and the head of the HFIR, which became a supervisory association responsible for the interorganizational cooperation (Omidvar, Zafari \& Derakhshan, 2009). For this reason, HFIR is scored relatively high in the dimension of closeness centrality but lower in degree centrality (e.g., MORHUD and BCC are scored 57,000 in comparison to HFIR's 35,000).

TABLE 3

CLOSENESS CENTRALITY

\begin{tabular}{lll}
\hline & In Farness & In Closeness \\
\hline Mean & 5833.092 & $\mathbf{5 8 3 3 . 0 9 2}$ \\
Std Dev & 5772.90 & $\mathbf{2 2 5 6 . 4 2 8}$ \\
Sum & 699971.000 & $\mathbf{6 9 9 9 7 1 . 0 0 0}$ \\
Variance & 33319334.000 & $\mathbf{5 0 9 1 4 6 7 . 5 0 0}$ \\
SSQ & 8081314816.000 & $\mathbf{4 6 9 3 9 7 0 9 4 4 . 0 0 0}$ \\
MCSSQ & 3998320128.000 & $\mathbf{6 1 0 9 7 6 0 6 4 . 0 0 0}$ \\
Euclidean Norm & 89896.133 & $\mathbf{6 8 5 1 2 . 5 6 3}$ \\
Minimum & 614.000 & $\mathbf{2 8 1 3 . 0 0 0}$ \\
Maximum & 14280.000 & $\mathbf{1 4 2 8 0 . 0 0 0}$ \\
Network & & \\
Centralization=34.41\% & & \\
& In Farness & In Closeness \\
MOFA & 614.000 & $\mathbf{6 5 4 9 . 0 0 0}$ \\
UNOCHA & 678.000 & $\mathbf{6 5 9 2 . 0 0 0}$ \\
MOI & 681.000 & $\mathbf{6 5 9 7 . 0 0 0}$ \\
IRCS & 687.000 & $\mathbf{6 5 9 1 . 0 0 0}$ \\
IFRC & 689.000 & $\mathbf{6 5 9 3 . 0 0 0}$ \\
WHO & 690.000 & $\mathbf{6 5 9 9 . 0 0 0}$ \\
BCC & 691.000 & $\mathbf{6 5 9 4 . 0 0 0}$ \\
OXFAM & 693.000 & $\mathbf{6 5 9 3 . 0 0 0}$ \\
HFIR & 701.000 & $\mathbf{6 5 9 5 . 0 0 0}$ \\
\hline SSQ Sim &
\end{tabular}

$\mathrm{SSQ}=$ Sum of Squares; MCSSQ=Mean Centered Sum of Squares

Table 4 presents the measure of centrality betweenness, which provides a third aspect of a structurally advantaged position - being between other actors. First we can see that there is high variation in actor betweenness (from 0.000 to 6200.859 ) and that there is a relatively high variation (std.dev. $=5772.90$, closer to the mean betweenness of 5833.092). The overall network centralization is relatively low (43.93\%). In terms of structural constraints, there is a relatively low amount of "power" in this network, although we know based on the previous measures that one-fourth of all connections can be made in this network without the aid of any intermediary - which explains why there can be a lot of "betweenness". MOFA, IRCS, MOI, and UNOCHA appear to be relatively much more powerful than others, as indicated by this measure. Table 4 also shows that OXFAM scored the ninth highest in its role as bridge among several organizations in the network. However, in its score of degree centrality, USAID is in a good position to gain information and resources from other actors in the network without the aid of an intermediary (relying on other organizations in reaching other actors in the network) rather than ISLAMRE and MUSAID. It should be pointed out that high betweenness centrality with low degree centrality actors such as USAID are often overlooked since they are not central to any single clique and 
instead reside on the periphery of several cliques; however, their ties are crucial for information flow. USAID coordinated with the IRCS to map humanitarian needs to use as a basis for relocating people into camps as it arrived at the affected region on December 30, 2003. From December 31 to January 5, the USAID team set up operations in Bam, based on assessments of needs and vulnerabilities of the affected communities, and coordinated with the $\mathrm{MOH}$, the UN organizations, and local and international humanitarian NGOs. During the disaster relief phase, USAID provided oversight on the distribution of international relief commodities and equipment, as well as providing emergency first responder training, in conjunction with the IFRC and the UN agencies (USAID, 2004). The fact that USAID is scored higher than pro-Islamic organizations such as the ISLAMRE $(19,000)$ and MUSAID $(8,000)$ may support the claim that in adverse situations, political and ideological rivals have been able to put aside their differences in the face of a humanitarian emergency. Despite the fact that post-disaster relief efforts did not catalyze any diplomatic activities and neither state organizations pursued the potential window, it is suggested that the US governmental aid agencies have successfully used disaster recovery to enhance their popular legitimacy and reputation.

TABLE 4

BETWEENNESS CENTRALITY

\begin{tabular}{lll}
\hline & Betweenness & nBetweenness \\
\hline Mean & 83.408 & $\mathbf{0 . 5 9 4}$ \\
Std Dev & 566.815 & $\mathbf{4 . 0 3 7}$ \\
Sum & 10009.000 & $\mathbf{7 1 . 2 7 9}$ \\
Variance & 321279.531 & $\mathbf{1 6 . 2 9 4}$ \\
SSQ & 39388376.000 & $\mathbf{1 9 9 7 . 6 0 7}$ \\
MCSSQ & 38553544.000 & $\mathbf{1 9 5 5 . 2 6 8}$ \\
Euclidean Norm & 6279.016 & $\mathbf{4 4 . 6 9 5}$ \\
Minimum & 0.000 & $\mathbf{0 . 0 0 0}$ \\
Maximum & 6200.859 & $\mathbf{4 4 . 1 5 9}$ \\
Network & & \\
Centralization=43.93\% & & \\
& Betweenness & $\mathbf{n B e t w e e n n e s s}$ \\
MOFA & 6200.859 & $\mathbf{4 4 . 1 5 9}$ \\
MOI & 277.295 & $\mathbf{1 . 9 7 5}$ \\
UNOCHA & 145.765 & $\mathbf{1 . 0 3 8}$ \\
IRCS & 131.762 & $\mathbf{0 . 9 3 8}$ \\
IFRC & 90.492 & $\mathbf{0 . 6 4 4}$ \\
BCC & 74.262 & $\mathbf{0 . 5 2 9}$ \\
USAID & 73.568 & $\mathbf{0 . 5 2 4}$ \\
WHO & 70.697 & $\mathbf{0 . 5 0 3}$ \\
OXFAM & 65.594 & $\mathbf{0 . 4 6 7}$ \\
\hline SSQ=Sum of Squares; MCSSQ=Mean Centered Sum of Squares
\end{tabular}

In order to corroborate these findings, we created an ego network of the top 24 organizations and calculated the number of brokerage roles played by them. Table 5 presents the frequency distribution from ego network analysis and G\&F Brokerage roles analysis. From G\&F brokerage role analysis, major governmental and local agencies such as MOFA, MOHAE, BCC, and TDMMC were major brokering agencies in this network. By following G\&F typology of brokerage roles, MOFA played brokerage roles most frequently. Especially during the recovery phase, MOFA's brokerage roles were consultant and liaison. When MOFA acts as a consultant, both sides are more motivated to make the connection work in 
order to preserve the tie with the consultant. It created connections for active interactions with other domestic agencies and served as a major collaboration facilitator among domestic and international agencies to deal with vulnerable communities during the recovery phase. The consultant role played by MOFA provides empirical evidence of the possible use of competent domestic agencies as brokers in disaster management systems. In the case of the 2003 Bam disaster response network, international agencies faced great difficulty in deciding with which domestic agencies they should form ties. Moreover, the sub-group of international agencies that was disconnected (with many structural holes) found that information is shared inefficiently or is not widely accessible. The brokerage analysis reveals that international agencies used MOFA in their search for potential ties. MOFA as a consultant provided necessary information on potential ties, leading to increased trust and lower costs for the international organizations (Uzzi, 1997). Drawing on the distance analysis, international agencies had roughly 2.164 degrees of separation from leading government ministries such as MOFA and MOI, meaning that peripheral agencies needed very few connections (two connections on average) to reach leading agencies. These figures support the evidence that MOFA played a significant consultant role in reducing search costs for international aid organizations.

TABLE 5

TOP 12 BROKERING ORGANIZATIONS IN 2003 BAM DISASTER RELIEF EFFORTS

\begin{tabular}{|c|c|c|c|c|c|c|}
\hline Name & Coordinator & Gatekeeper & Representative & Consultant & Liaison & Total \\
\hline SWO & & & & 2 & & 2 \\
\hline ISLAMRE & 2 & 1 & 1 & & & 4 \\
\hline UNFPA & & & & 2 & & 2 \\
\hline TDMMC & & 2 & 2 & 2 & & 6 \\
\hline MUSAID & & 1 & 1 & & & 2 \\
\hline IFRC & & & & 2 & & 2 \\
\hline MOFA & & & & 38 & 5 & 43 \\
\hline UNOCHA & & & & 2 & & 2 \\
\hline MOHAE & & & & 8 & & 8 \\
\hline $\mathrm{BCC}$ & & 2 & 2 & 4 & & 8 \\
\hline IRCS & & 2 & 2 & & & 4 \\
\hline MOI & & & & 2 & & 2 \\
\hline
\end{tabular}

Similarly, BCC served as a significant broker for types of gatekeeper, representative, and consultant roles; thus it maintained close coordination with governmental and international agencies and NGOs. It is suggested that joint operations of international organizations needed to pass the gate of both public and international organizations. At the same time, collaborations from all different levels of jurisdictions in the public sector were played within TDMMC, ISLAMRE, MOI, SWO, and IKRF (consultant role) where coordination among different groups of agencies was played by MOFA (liaison role). As shown in Table 5, the major brokerage roles in this network were played by both domestic public (administrative) and international aid agencies. Thus, the G\&F brokerage analysis results are compatible with the previous network analysis and the network map.

\section{Summing Up}

The applications of network analysis to international disaster management suggest that different network components have distinct effects on coordination among all actors engaged in disaster response and relief efforts. The descriptive findings presented in this paper indicate the role of brokers as a supportive mechanism in building reputational capital. Iranian governmental and international 
coordinating agencies such as MOFA and UNOCHA became key brokers to facilitate coordination for reducing disaster vulnerabilities. We find that in the case of 2003 Bam earthquake, state organizations such as MOFA and MOHAE were found to have relatively more ties in the network. These actors were able to create patterns of interaction that were crucial to bridge other actors. MOFA and MOHAE served as key brokers for consultants who were conduits for access to information and thus could directly gain information and power, and control benefits to keep them from occupying a strategic position on the network. In addition to high degrees of centrality, MOFA fulfilled a significant consultant role in reducing search costs for international aid organizations.

Regarding the brokerage roles played by international agencies such as UNOCHA, IFRC, and IRCS, the G\&F brokerage analysis indicates that these international agencies played very few brokerage roles across different categories. If the disaster coordination activities were managed well, then the G\&F brokerage analysis would probably show a higher number of brokerage roles. These figures support the assessment that UNOCHA and the UNISDR had some difficulties in setting up their coordination system since coordination efforts were already deployed by the Iranian government and the IRCS (Wood, 2004). The fact that UNOCHA and USAID have a high centrality degree despite few brokerage roles can explain why UNOCHA did not become a leading coordination actor but had a built-in coordination structure that enabled them to frequently communicate with advocacy organizations that engaged in the recovery efforts. (ibid.) Moreover, Iranian governmental councils became an increasingly political site on the basis of an expert authority that can be used by government to legitimize disaster management activities.

\section{CONCLUSION}

Large scale natural disasters should be treated as international political events. Natural disasters impose constraints in enhancing collaboration more than in "good times". When viewed from the disaster diplomacy approach, the very nature of natural disasters requires quick and immediate coordinative actions to reduce disaster vulnerabilities that may positively affect relations amongst states that are not prone to cooperate in "good times". This underscores the crucial, yet often neglected, role that brokers might play within governance networks during the phase of disaster response and relief efforts. Where broad-based collaboration focuses on norms of trust and reciprocity, coordination focuses on structural embeddedness that facilitates high levels of interaction and collaboration amongst a wide array of actors. For that, reputational capital could be used strategically by actors in disaster response systems in bringing added value to lay the groundwork for later diplomacy. Brokers who are able to mobilize their reputational capital are able to serve as major facilitators in promoting collaboration in the system. In order to preserve and develop this intangible asset, brokers need to identify contact points for mediation through access to resources and proper knowledge on local disaster vulnerabilities.

The 2003 Bam earthquake yielded insights into the importance of investment in reputational capital (e.g., in reputation building and monitoring) as a basis for both good governance and disaster diplomacy. In the case of the 2003 Bam earthquake, state organizations and public domestic organizations developed joint projects and networking with international humanitarian aid and coordination organizations by encouraging marginalized communities such as women, children, refugees, and the elderly to participate in disaster recovery and assessment of risks. This paper suggests that partnerships between state agencies and international aid agencies are crucial in terms of reputational capital, in the broader social, political, and economic context, by opening up possibilities of providing an associational sphere, which enables reduction of the long-term Iranian government suspicion of INGOs. Both state agencies and international organizations filled the structural holes of the network to maintain the capacities and involvement in the government disaster management system of communities at risk. However, except for a few international agencies such as the IFRC and OCHA, other international organizations rarely played brokerage roles to coordinate more peripheral organizations engaged in the disaster response network (Brass, 2012). One possible explanation may go back to political and ideological factors such as Iran's isolation from the international community and its initial reluctance to accept intervention from foreign agencies, which are suggested to endanger the coordination facilities of international aid agencies. Further, in the case of 
USAID, the brokerage analysis is not compatible with the relatively high degree of centrality. USAID, despite emergency and coordination capacities, did not have long-term relations with Iranian domestic organizations and the resulting absence of reputational capital prevented it from serving brokerage roles in the system. Similarly, ISLAMRE and MUSAID, both international relief and development pro-Islamic NGOs, did not hold high degrees of centrality but served brokerage roles, namely representative and gatekeeper, that did not need to pass through the "gate" of the Iranian government to engage in disaster response operations as did other external agencies.

Thus, by studying the role of brokers in times of disaster, scholars may better address the way structural positions in a network can enhance coordination and lay the foundation for building reputational capital to impact the quality of diplomatic-related activities in the long run. As our results are limited to the case of 2003 Bam earthquake insider trading, further research will be necessary to examine a deeper facet of reputational capital such as cognitive and relational associated with a set of norms and values and mutual trust.

\section{REFERENCES}

Berardo, R., \& Scholz, J. T. (2010). Self-organizing policy networks: risk, partner selection, and cooperation in estuaries. American Journal of Political Science 54(3), 632-649.

Borgatti, S. P., Everett, M. C., \& Freeman, L. C. (2002). UCINET for Windows: Software for social network analysis. Cambridge, MA: Analytic Technologies.

Börzel, T. (1998). Rediscovering Policy Networks as a Form of Modern Governance. Journal of European Public Policy, 5(2), 354-349.

Brass, J. N. (2012). Blurring Boundaries: The Integration of NGOs into Governance in Kenya. Governance, 25(2), 209-235.

Burt, R. S. (1992). Structural holes. Cambridge, MA: Harvard University Press.

Comfort, L. K., \& Haase, T. W. (2006). Communication, coherence, and collective action: The impact of Hurricane Katrina on communications infrastructure. Public Works Management and Policy, $10(3), 328-343$.

Comfort, L. K., Kilkon, K., \& Zagorecki, A. (2004). Coordination in rapidly evolving disaster response systems: The role of information. American Behavioural Scientist, 48, 295.

Coppola D. P. (2011). Introduction to International Disaster Management, Second Edition. Oxford, UK: Elsevier/Butterworth-Heinemann.

deLeon, P., \& Varda, D. M. (2009). Toward a theory of collaborative policy networks: Identifying structural tendencies. Policy Studies Journal, 37(1), 59-74.

Dentchev, N. A., \& Heene, A. (2004). Managing the reputation of restructuring corporations: Send the right signal to the right stakeholder. Journal of Public Affairs, 4(1), 56-72.

Drabek, T. E. (2003). Strategies for coordinating disaster responses. Boulder, CO: Institute of Behavior Sciences.

Fombrun, C. (1996). Reputation: Realizing value for the corporate image. Cambridge, MA: Harvard Business School Press.

Gajda, R. (2004). Utilizing collaboration theory to evaluate strategic alliances. American Journal of Evaluation, 25, 65-77.

Gardberg, N. A., \& Fombrun, C. J. (2006). Corporate Citizenship: Creating intangible assets across institutional environments. Academy of Management Review, 31(2), 329-346.

Gould, R. V., \& Fernandez, R. M. (1989). Structures of mediation: A formal approach to brokerage in transaction networks. Sociological Methodology, 19, 89-126.

Gulati, R., \& Martin, G. (1999). Where do interorganizational networks come from? American Journal of Sociology, 104, 1439-1493.

Hall, R. (1993). A framework linking intangible resources and capabilities to sustainable competitive advantage. Strategic Management Journal, 14(8), 607-618. 
Hanaki, N., Peterhansl, A., Dodds, P. S., \& Watts, D. J. (2007) Cooperation in evolving social networks. Management Science, 53(7), 1036-1050.

Hanneman, R. A. (2001). Introduction to social network methods. Riverside, CA: University of California Riverside.

Hanneman, R. A., \& Riddle, M. (2005). Introduction to social network methods. Berkeley, CA: University of California Press.

Hogue, T. (1993). Community-based collaboration: Community wellness multiplied. Bend, OR: Chandler Center for Community Leadership Retrieved from http://crs.uvm.edu/nnco/collab/wellness.html

HFIR. (2009). The collection of Bam reconstruction progress reports (2004-2009). Tabriz, Iran: Housing Foundation of Islamic Revolution.

Ingold, K. (2011). Network Structures within Policy Processes: Coalitions, Power, and Brokerage in Swiss Climate Policy. Policy Studies Journal, 39(3), 435-459.

Ireni-Saban, L. (2015) Entrepreneurial Brokers in Disaster Response Network in Typhoon Haiyan in the Philippines. Public Management Review, 17(10), 1496-1517.

Kapucu, N. (2006) Interagency communication networks during emergencies: Boundary spanners in multiagency coordination. American Review of Public Administration, 36, 207-225.

Kapucu, N. T., Arslan, \& Collins, L M. (2010). Examining intergovernmental and interorganizational response to catastrophic disasters: Toward a network-centered approach. Administration \& Society, 42, 222.

Kapucu, N., Augustin, M-E., \& Garayev, V. (2009). Interstate partnerships in emergency management: Emergency management assistance compact (EMAC) in response to catastrophic disasters. Public Administration Review, 69(2), 297-313.

Keast, R., Mandell, M. P., Brown, K., \& Woolcock, G. (2004). Network structures: Working differently and changing expectations. Public Administration Review, 64(3), 363-371.

Kelman, I. (2006). Acting on disaster diplomacy. Journal of International Affairs, 59(2), 215-240.

Koliba, C., Meek, J., \& Zia, A. (2010). Governance networks in public administration and public policy. Boca Raton, FL: CRC Press.

Lassa, J. A. (2012). Post Disaster Governance, Complexity and Network Theory: Evidence from Aceh, Indonesia After the Indian Ocean Tsunami 2004. Working Paper No. 1, IRGSC working papers Series, 1-19.

Lubell, M. (2013). Governing Institutional Complexity: The Ecology of Games Framework. Policy Studies Journal, 41(3), 537-559.

Lubell, M., Henry, A. D., \& McCoy, M. (2010). Collaborative institutions in an ecology of games. American Journal of Political Science, 54(2), 287-300.

Magsino, S. L. (ed). (2009). Applications of social network analysis for building community disaster resilience: workshop summary. Washington, DC: Board on Earth Sciences and Resources Division on Earth and Life Studies, The National Academies Press.

Mann, H., Cao, Y., \& Jit Singh Mann, I. (2011). Strategy Implementation Tool: Supply Chain Contract. IUP Journal of Business Strategy, 8(2), 34-48.

Marsden, P. V. (1982). Brokerage behavior in restricted exchange networks. In: Peter V Marsden \& Nan Lin (eds) Social structure and network analysis. Beverly Hills, CA: Sage, 201-218.

Mashaw, J. L. (2006). Accountability and institutional design: Some thoughts on the grammar of governance. In: Michael K. Dowdle (ed) Public accountability: Designs, dilemmas and experiences. Cambridge: Cambridge University Press, 115-156.

McEntire, D. A. (2002). Coordinating multi-organizational responses to disaster: Lessons from the March 28, 2000, Fort Worth tornado. Disaster Prevention and Management, 11(5), 369-379.

Meuleman, M., Amess, K., Wright, M., \& Scholes, L. (2009). Agency, strategic entrepreneurship and the performance of private equity backed buyouts. Entrepreneurship: Theory \& Practice, 33, 213 239.

Mitchell, J. K. (2006). The primacy of partnership: Scoping a new national disaster recovery policy. Annals of the American Academy of Political and Social Science, 604, 228-255.

112 Journal of Management Policy and Practice Vol. 20(3) 2019 
Morris, J.C, Elizabeth D Morris \& Dale M Jones (2007) Reaching for the Philosopher's Stone: Contingent Coordination and the Military's Response to Hurricane Katrina. Public Administration Review, 67(Special issue), 94-106.

Moynihan, D. P. (2012). Extra-network organizational reputation and blame avoidance in networks: The Hurricane Katrina example. Governance, 25(4), 567-588.

Mueller, M., Schmidt, A., \& Kuerbis, B. (2013). Internet security and networked governance in international relations. International Studies Review, 15(1), 86-104.

Omidvar, B., Zafari, H., \& Derakhshan, S. (2009). Reconstruction management policies in residential and commercial sectors after the 2003 Bam earthquake in Iran. Natural Hazards, 54, 289-306.

Pinera, J-F., Reed, R. A., \& Njiru, C. (2005). Restoring sanitation services after an earthquake: Field experience in Bam, Iran. Disasters, 29(3), 222-236.

Polzer, J. T. (2004) How subgroup interests and reputations moderate the effect of organizational identification on cooperation. Journal of Management, 30(1), 71-96.

Robinson, D. T., \& Stuart, T. E. (2007). Network effects in the governance of strategic alliances. Journal of Law, Economics, \& Organization, 23, 242-273.

Rowley, T., Behrens, D., \& Krackhardt, D. (2000). Redundant governance structures: An analysis of structural and relational embeddedness in the steel and semiconductor industry. Strategic Management Journal, 21, 369-386.

Shane, S., \& Cable, D. (2002). Network ties, reputation, and the financing of new ventures. Management Science, 48, 364-381.

Singh, J. P. (2013). Information technologies, meta-power, and transformations in global politics. International Studies Review, 15, 5-29.

Smaldino, P. E., \& Lubell, M. (2014). Institutions and cooperation in an ecology of games. Artificial Life, 20, 207-221.

Thompson, G. F (2003) Between hierarchies and markets: The logic and limits of network forms of organization. Oxford, UK: Oxford University Press.

UNOCHA. (2004). Flash Appeal, Bam Earthquake of 26 December 2003: Islamic Republic of Iran relief, recovery and immediate rehabilitation. United Nations. Retrieved from http://www.unicef.org/emerg/files/Flash_Appeal_8_January_2004_New.pdf

USAID (United States Agency for International Development). (2004). Estimated damage caused by the Bam earthquake. Retrieved from http://www.usaid.gov/fani/ch04/windows.htm

Uzzi, B. (1997). Social structure and competition in interfirm networks: The paradox of embeddedness. Administrative Science Quarterly, 42, 35-67.

Varda, D. M., Forgette, R., Banks, D., \& Contractor, N. (2009). Social network methodology in the study of disasters: Issues and insights prompted by post-Katrina research. Population Research and Policy Revue, 28, 11-29.

Wallensteen, P., \& Svensson, I. (2014). Talking Peace: International Mediation in. Armed Conflicts, Journal of Peace Research, 51(2), 315-327.

Wise, C. R. (2006). Organizing for homeland security after Katrina: Is adaptive management what's missing? Public Administration Review, 66(3), 302-318.

Wood, J. (2004). Improving NGO coordination: Lessons from the Bam earthquake. Humanitarian Exchange Magazine, 27, 27-30. 


\section{APPENDIX A \\ TOP 45 ORGANIZATIONS IN THE 2003 BAM DISASTER RESPONSE NETWORK}

\begin{tabular}{|c|c|c|}
\hline Number & Abbreviation & Organization \\
\hline 1 & MOFA & Ministry of Foreign Affairs \\
\hline 2 & UNOCHA & $\begin{array}{l}\text { United Nations Office for the Coordination of Humanitarian } \\
\text { Affairs }\end{array}$ \\
\hline 3 & MOI & Ministry of Interior \\
\hline 4 & IMSURT & International Medical Surgical Response Team \\
\hline 5 & IRCS & Iranian Red Crescent Society \\
\hline 6 & HAZ HOS & Hazrat-e-Fatemeh Hospital \\
\hline 7 & WHO & World Health Organization \\
\hline 8 & KS HOS & Kashani Hospital \\
\hline 9 & UNDAC & United Nations Disaster Assessment and Coordination \\
\hline 10 & IFRC & International Federation of Red Cross \\
\hline 11 & UNICEF & United Nations Children's Fund \\
\hline 12 & USAID & United States Agency for International Development \\
\hline 13 & MOHUD & Ministry of Housing and Urban Development \\
\hline 14 & $\mathrm{BCC}$ & Bam City Council \\
\hline 15 & OXFAM & Oxford Committee for Famine Relief \\
\hline 16 & MOHAE & Ministry of Health and Medical Education \\
\hline 17 & FEMA & Federal Emergency Management Agency \\
\hline 18 & SWO & The State Welfare Organization \\
\hline 19 & EU E AID & European Union Humanitarian Aid Office \\
\hline 20 & HFIR & Islamic Revolutionary Housing Foundation \\
\hline 21 & MOWFA & Ministry of Economy and Finance Affairs \\
\hline 22 & EXPE C & Expediency Discernment Council \\
\hline 23 & IKRF & Imarn Khan Flood Relief Foundation \\
\hline 24 & ASS EX & Assembly of Experts \\
\hline 25 & UNFPA & United Nations Population Fund \\
\hline 26 & UNDP & United Nations Development Programme \\
\hline 27 & TDMMC & Tahran Disaster Mitigation and Management Organization \\
\hline 28 & UNDRO & United Nations Disaster Relief Organization \\
\hline 29 & $\mathrm{SAV} \mathrm{CH}$ & Save the Children \\
\hline 30 & DWBOR & Doctors Without Borders \\
\hline 31 & MERC & Mercy Corps \\
\hline 32 & MODF & Ministry of Defense and Logistics \\
\hline 33 & INT RSC & International Rescue Committee \\
\hline 34 & ISLAMRE & Islamic Relief \\
\hline 35 & INTEL MED & International Medical Corps \\
\hline 36 & APCL & Association for Protecting Child Laborers \\
\hline 37 & W BANK & World Bank \\
\hline 38 & IIEES & International Institute of Seismology and Earthquake Engineering \\
\hline 39 & MOC & Ministry of Commerce \\
\hline 40 & IAMA & Iranian American Medical Association \\
\hline 41 & CARE & Cooperative for Assistance and Relief Everywhere \\
\hline 42 & MUSAID & Muslim Aid \\
\hline 43 & IRIA & Islamic Republic of Iran Army \\
\hline 44 & $\mathrm{COP}$ & Maryland-based Children of Persia \\
\hline 45 & ERFO & Earthquake Relief Funds for Orphans \\
\hline
\end{tabular}

